\title{
Neural network-based method for anti-glare glass preparation process parameters optimization
}

\author{
Jianli $\mathrm{Yu}^{\mathrm{a}}$, Hongqi Huang ${ }^{\mathrm{b}}$, Xiaojuan $\mathrm{Niu}^{\mathrm{c}}$ \\ Zhengzhou University of Aeronautical,School of Management Science Engineering, \\ Zhengzhou, China \\ ajj1837@163.com, b760990540@qq.com, nxj@zzia.edu.cn
}

Keywords: Neural network; Parameter optimization; Anti-glare glass

\begin{abstract}
Along with the urban development, the application of anti-glare glass is more and more widely, high transmittance and low reflection of glass manufacturing technology research is of great significance. Because of the complexity of the anti-glare glass preparation technology, anti-glare glass transmittance is affected by multiple factors. Because of complexity nonlinear relation between the real production data, response surface method can't solve the problem of anti-glare glass preparation process parameters optimization. The BP neural network is proposed in this paper to structure the complex nonlinear model between the design vector with the response vector. BP neural network has high learning and representation ability and have ability by establishing a good mapping model. Using BP neural network model of high generalization ability on the optimal parameter combination optimization search about the corrosion condition of glass, with less test data to get the ideal parameter design.
\end{abstract}

\section{Introduction}

In recent years, high reflection ability of glass curtain wall also bring light pollution of the environment problem and affect people's lives and health ${ }^{[1]}$. Anti-glare glass is a kind of ideal method to solve the problem of light pollution that have low reflection compared with common glass.

Using chemical etching method ${ }^{[2]}$ carry out on the glass surface acidification treatment craft which has been widely applied in commercial production. Because of the complexity of the anti-glare glass preparation technology, anti-glare glass transmittance is affected by multiple factors and the real production data exist the nonlinear relation that the more common model can't solve the problem of anti-glare glass preparation process parameters optimization. In order to solve this problem, this paper proposes a way to establish the complex nonlinear model by using the BP neural network to achieve anti-glare glass preparation process parameters optimization.

Experimental data of temperature factor has four levels, time factor has six levels. Coding the level, the level of temperature $\left(\mathrm{x}_{1}\right) 15^{\circ} \mathrm{C}, 20^{\circ} \mathrm{C}, 25^{\circ} \mathrm{C}$ and $30^{\circ} \mathrm{C}$ is set to $1,2,3,4$ level of time $\left(\mathrm{x}_{2}\right) 3 \mathrm{~min}, 5 \mathrm{~min}$, $8 \mathrm{~min}, 10 \mathrm{~min}, 15 \mathrm{~min}, 20 \mathrm{~min}$ is set to $1,2,3,4,5,6$. To eliminate the dimension of data(refer with: Table.1), the transmittance (y) is standardized (Y).

Table.1 Original data

\begin{tabular}{cccccccccccccccccccc}
\hline $\begin{array}{c}\text { Trial } \\
\text { no. }\end{array}$ & $\mathrm{x}_{1}$ & $\mathrm{x}_{2}$ & $\mathrm{y} \%$ & $\mathrm{Y}$ & $\begin{array}{c}\text { Trial } \\
\text { no. }\end{array}$ & $\mathrm{x}_{1}$ & $\mathrm{x}_{2}$ & $\mathrm{y} \%$ & $\mathrm{Y}$ & $\begin{array}{c}\text { Trial } \\
\text { no. }\end{array}$ & $\mathrm{x}_{1}$ & $\mathrm{x}_{2}$ & $\mathrm{y} \%$ & $\mathrm{Y}$ & $\begin{array}{c}\text { Trial } \\
\text { no. }\end{array}$ & $\mathrm{x}_{1}$ & $\mathrm{x}_{2}$ & $\mathrm{y} \%$ & $\mathrm{Y}$ \\
\hline $\mathbf{1}$ & 1 & 1 & 86.9 & 0.65051 & $\mathbf{7}$ & 2 & 1 & 78.1 & -1.36398 & $\mathbf{1 3}$ & 3 & 1 & 82.5 & -0.35673 & $\mathbf{1 9}$ & 4 & 1 & 87.5 & 0.78786 \\
$\mathbf{2}$ & 1 & 2 & 83.1 & -0.21938 & $\mathbf{8}$ & 2 & 2 & 80.4 & -0.83746 & $\mathbf{1 4}$ & 3 & 2 & 77.3 & -1.54711 & $\mathbf{2 0}$ & 4 & 2 & 83.7 & -0.08203 \\
$\mathbf{3}$ & 1 & 3 & 87.2 & 0.71919 & $\mathbf{9}$ & 2 & 3 & 88.5 & 1.01678 & $\mathbf{1 5}$ & 3 & 3 & 88.1 & 0.92521 & $\mathbf{2 1}$ & 4 & 3 & 77.4 & -1.52422 \\
$\mathbf{4}$ & 1 & 4 & 86.3 & 0.51316 & $\mathbf{1 0}$ & 2 & 4 & 89.9 & 1.33727 & $\mathbf{1 6}$ & 3 & 4 & 88.2 & 0.94811 & $\mathbf{2 2}$ & 4 & 4 & 89.3 & 1.19992 \\
$\mathbf{5}$ & 1 & 5 & 81.8 & -0.51698 & $\mathbf{1 1}$ & 2 & 5 & 82.8 & -0.28806 & $\mathbf{1 7}$ & 3 & 5 & 89.6 & 1.26859 & $\mathbf{2 3}$ & 4 & 5 & 83.3 & -0.1736 \\
$\mathbf{6}$ & 1 & 6 & 83.8 & -0.05914 & $\mathbf{1 2}$ & 2 & 6 & 85.8 & 0.3987 & $\mathbf{1 8}$ & 3 & 6 & 74 & -2.30254 & $\mathbf{2 4}$ & 4 & 6 & 81.9 & -0.49408 \\
\hline
\end{tabular}




\section{Response surface method}

Response surface method ${ }^{[3]}$ is a more common method of parameter optimization by building regression model between the response variables and significant impact factor and optimizing the process to determine the parameters of the optimal level combination. The paper establish Response surface model between the design vector, temperature $\left(\mathrm{x}_{1}\right)$ and time $\left(\mathrm{x}_{2}\right)$, and the response vector, transmittance(Y), by using Minitab15 software. Regression analysis and variance analysis of the results as shown in Table 2:

Table. 2 Regression analysis and Variance analysis

\begin{tabular}{ccc}
\hline \multicolumn{3}{c}{ Response surface model } \\
\hline Independent variable & $\mathrm{T}$ & $\mathrm{P}$ \\
constant & -0.58 & 0.567 \\
$\mathrm{x}_{1}$ & -0.28 & 0.781 \\
$\mathrm{x}_{2}$ & 1.60 & 0.127 \\
$\mathrm{x}_{1}{ }^{*} \mathrm{x}_{1}$ & 0.31 & 0.757 \\
$\mathrm{x}_{2}{ }^{*} \mathrm{x}_{2}$ & -1.67 & 0.113 \\
$\mathrm{x}_{1}{ }^{\mathrm{x}_{2}}$ & -0.26 & 0.801 \\
\hline & $\mathrm{Y}=-1.04-0.32 \mathrm{x}_{1}+1.07 \mathrm{x}_{2}+0.067 \mathrm{x}_{1}{ }^{2}$ \\
Variance analysis & $-0.142 \mathrm{x}_{2}{ }^{2}-0.029 \mathrm{x}_{1} \mathrm{x}_{2}$ \\
& $\mathrm{~F}=0.63$ & $\mathrm{P}=0.676$ \\
\hline Degree of fitting & $\mathrm{R}=15 \%$ & $\mathrm{R}_{\text {-adj }}=0.0 \%$ \\
\hline
\end{tabular}

Regression analysis results of response surface method (refer with: Table.2) show that no significant linear correlation between factors and response; In analysis of variance, the P value (0.676) shows that the regression process estimation model in the level of 0.05 is not significant; A fit of the linear regression equation $\mathrm{R}=15 \%$, but due to no significant linear correlation between factors and response, adjusted the fit of the variance is $0.0 \%$. Thus, response surface model is not good.

The construction and analysis of response surface method show that the corrosion of glass controllable factors (temperature and time) and response (transmittance) and regression model represent no significant. Thus relationship among the temperature, time and transmittance is not easy to find. Nonlinear model of optimization design are needed to solve the problem of not ideal regression model. BP neural network ${ }^{[4]}$ is a kind of multiple layer forward neural network, with strong self-organizing, self-adapting, self-learning ability and generalization ability ${ }^{[5]}$, and can realize arbitrary nonlinear mapping from input to output ${ }^{[6]}$. The BP neural network is used to establish the nonlinear relationship between temperature, time and transmittance and solve the shortage of the Response surface method.

\section{BP neural network model}

BP neural network model is a common method of artificial neural network. The topological structure(refer with: Fig.1) include the input layer, hidden layer and output layer.

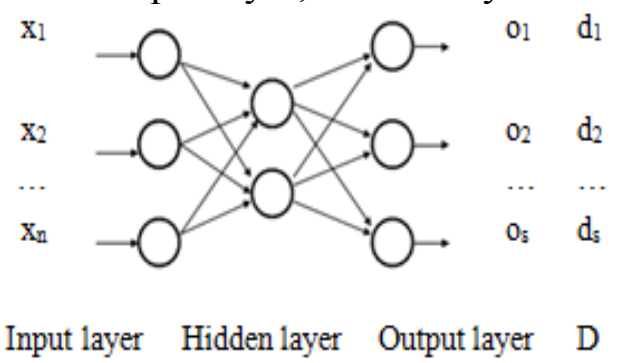

Figure.1 BP neural network model structure

BP neural network can build nonlinear mapping between the input vector $\mathrm{X}$ and the expected output vector $\mathrm{D}$, output vector of output layer $\mathrm{O}$. The learning process of $\mathrm{BP}$ neural network is composed of forward and reverse propagation. Calculation the error $e$ between desired output vector $\mathrm{D}$ and actual output vector $\mathrm{O}$. If the error without achieve network error precision, back propagation 
neural network is used for layered transmission error to modify the connection weights and threshold values.Back propagation learning rule is the gradient descent method.For narrowing the desired output vector $\mathrm{D}$ and the actual output vector $\mathrm{O}$ error, firstly calculates the error signal of each layer, and then to adjust each layer connection weights to make the network error sum of squares of reduced constantly until the desired output vector $\mathrm{D}$ and the error $e$ of the actual output vector $\mathrm{O}$ meet network precision requirement.

3.1 Construction of BP neural network optimization model

Minitab software are used to get the transmittance of main effect diagram (refer with: Fig.2) and the contour map among the temperature, time and the transmittance(refer with: Fig.3). In the main effect diagram, the response variable, transmittance, is larger-the-better characteristics, the main effect of four parameters level value of the temperature factor is relatively close, and the level of 4 main effect of time factor value is the highest. In the contour map, transmittance of the glass is the highest when the time factor in level of 3, 4, 5 .
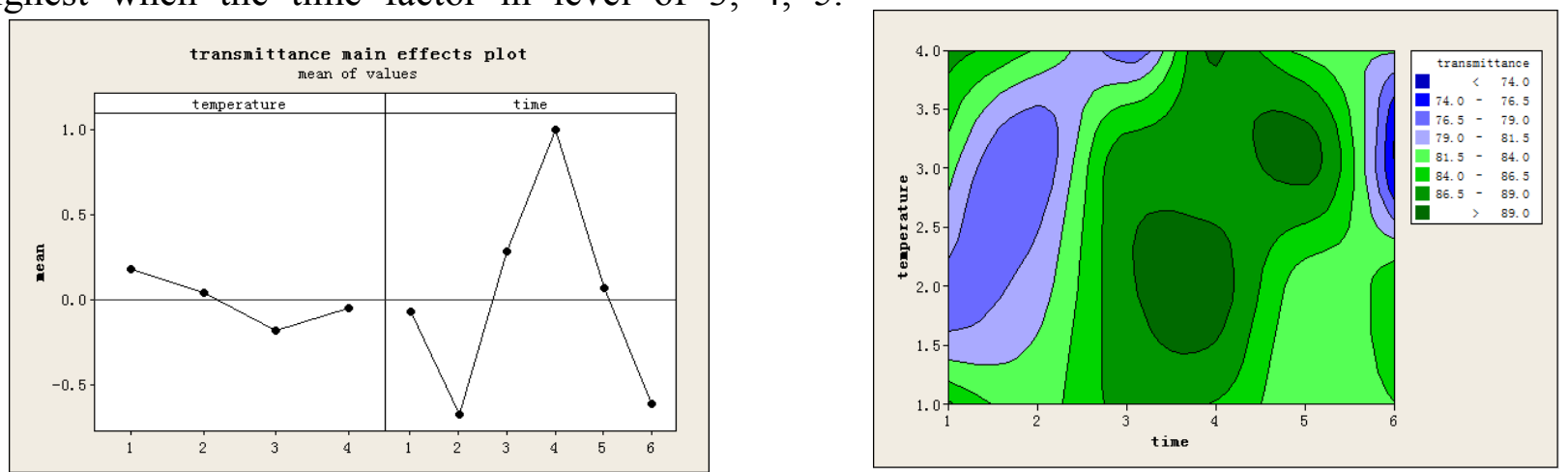

Comprehensive consideration after analysis, the BP neural network model parameters optimization temperature level range is set in interval $[1,4]$, and the time level rang is set in interval $[3,5]$.

Figure. 2 Main effect diagram

Figure. 3 Contour map

Network training statement:net=newff(minmax $(p),[10,1],\{$ 'tansig', 'purelin'\}, 'trainlm'). And the accuracy of training target is 0.001 ; training speed is 0.001 ; training cycles is 300 .

Mean square error of BP neural network is $6.8855 \mathrm{e}^{-4}$, and network training cycle in 35 steps fulfill the requirements of training precision(refer with:Fig.4).

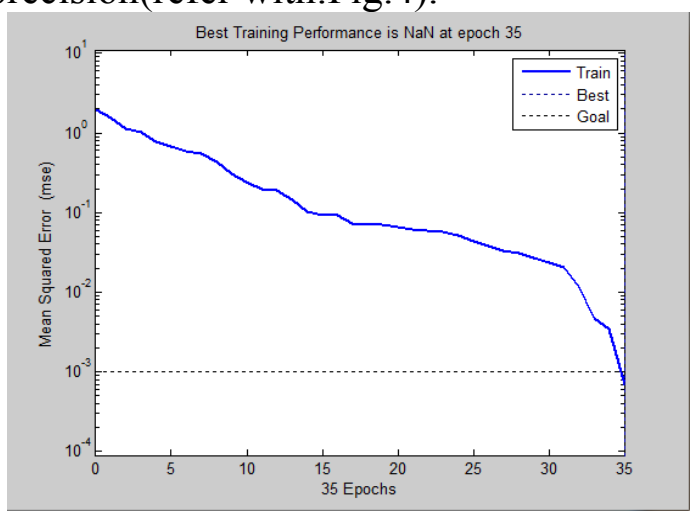

Figure.4 Training error curve

3.2 The Optimization search method of BP neural network

In a narrow range of parameter optimization, increasing factor level assignment and using the BP neural network generalization ability to search the optimal parameters combination, for achieving highest response variable transmittance.

Iteration 1: Temperature $\left(\mathrm{x}_{1}\right)$ set the level of $1,2,2.5,3,1.5,3.5,4$, time $\left(\mathrm{x}_{2}\right)$ set the level 3, 3.5, 4, 4.5, 5, and make full factorial experiment design. In iteration 1, two factors respectively signified $\mathrm{x}_{11}, \mathrm{x}_{21}$. Using generalization ability of BP neural network search optimization. Matlab statements for $\mathrm{a}=\left[\begin{array}{ll}\mathrm{x}_{11} & \mathrm{x}_{21}\end{array}\right]$ '; $\mathrm{Y}_{1}=\operatorname{sim}($ net, a). The optimal predicted result(refer with:Table.3) is $(2.5,3.5)$. The optimal parameter combination standardization of transmittance increased to 1.8433 .

Iteration 2: The optimal parameter combination $(2.5,3.5)$ in iteration 1 up and down in a small scale to set the temperature $\mathrm{x} 1$ level of 2.2, 2.3, 2.4, 2.5, 2.6, 2.7, 2.8 and the time $\mathrm{x} 2$ level of 3.2, 3.3, 
3.4, 3.5, 3.6, 3.7, 3.8, and make full factorial experiment design. In iteration 2, two factors respectively signified $\mathrm{x}_{12}, \mathrm{x}_{22}$. The optimal predicted result(refer with:Table.4) is $(2.4,3.3)$. The optimal parameter combination standardization of transmittance increased to 1.8685 .

Table 3 The predicted results of iteration 1

\begin{tabular}{|c|c|c|c|}
\hline Trial no. & $\mathrm{x}_{11}$ & $\mathrm{X}_{21}$ & $\mathrm{Y}_{1}$ \\
\hline 1 & 1 & 3 & 0.7127 \\
\hline 2 & 1 & 3.5 & 1.6629 \\
\hline 3 & 1 & 4 & 0.5107 \\
\hline \multicolumn{4}{|c|}{$\cdots$} \\
\hline 17 & 2.5 & 3.5 & 1.8433 \\
\hline \multicolumn{4}{|c|}{$\ldots$} \\
\hline 34 & 4 & 4.5 & 0.0996 \\
\hline 35 & 4 & 5 & -0.187 \\
\hline
\end{tabular}

Table 4 The predicted results of iteration 2

The response variable transmittance (\%) average of the original data is 84.0583 and the standard deviation is 4.36836 . Thus, the parameter optimization optimization value(1.8685) of BP neural network is transformed into true value (\%) of 92.22. Thus, the parameter optimization method proposed in this paper set the glass corrosion conditions that temperature of $22{ }^{\circ} \mathrm{C}$ and time of $8.6 \mathrm{~min}$ to increase anti-glare glass transmittance to $92.22 \%$.

\section{Summary}

BP neural network have higher mapping ability for variables affected by multiple factors. Using generalization ability of BP neural network to search the optimal parameters combination, namely in the building of the nonlinear regression model to search the most advantage to achieve the highest response variable transmittance and search results show that the nonlinear regression model based on BP neural network parameter optimization method of parameter combination can effectively improve the transmittance of anti-glare glass. To sum up, the parameters of the nonlinear regression optimization method based on BP neural network is feasible, effective and can make up for the inadequacy of the response surface method.

\section{Acknowledgements}

This work is supported by the Natural Science Foundation of Zhengzhou City under Grant No. 131PPTGG418-2

\section{References}

[1]Fang Qiao-li, Zhou Jian, Xie Li, et al. Guangzhou glass curtain wall building light environment monitoring and evaluation in summer. Environmental Pollution \& Control, 2013, 35(11):33-36.

[2]Elmer T H,Walters H,U.S.Patent,4019884(1977).

[3]G.Elatharasan,V.S.Senthil Kumar. Modelling and Optimization of Friction Stir Welding Parameters for Dissimilar Aluminium Alloys Using RSM. Procedia Engineering, 2012, 38: 3477-3481.

[4]Yu Feng, Xu Xiao-zhong. A short-term load forecasting model of natural gas based on optimized genetic algorithm and improved BP neural network.Applied Energy, 2014, 134:102-113.

[5]Ali N. Celik, Tariq Muneer. Neural network based method for conversion of solar radiation data. Energy Conversion and Management, 2013, 67: 117-124. 
[6]Bai He-ming, Shen Run-ping, Shi Hua-ding, et al. Forecasting model of air pollution index based on BP neural network[J]. Environmental Science \& Technology, 2013, 36(3):186-189. 